\title{
HBx gene transfection affects the cycle of primary renal tubular epithelial cells through regulating cyclin expression
}

\author{
WENLUN HAN*, MEILIANG LUO*, MENGYING HE, YUNYUN ZHU, YU ZHONG, \\ HUIDENG DING, GANG HU, LIANSHENG LIU, QIN CHEN and YING LU
}

\author{
Department of Nephrology, Tongde Hospital of Zhejiang Province, Hangzhou, Zhejiang 310012, P.R. China
}

Received May 27, 2017; Accepted February 27, 2018

DOI: $10.3892 / \mathrm{mmr} .2018 .9197$

\begin{abstract}
Hepatitis B virus X protein ( $\mathrm{HBx}$ ) has been previously demonstrated to be associated with the regulation of cell proliferation; however, the exact mechanisms underlying this effect remain unclear. The present study aimed to investigate the regulatory mechanism of $\mathrm{HBx}$ on the cycle progression of primary renal tubular epithelial cells. Primary renal tubular epithelial cells of Sprague Dawley (SD) rats were separated and cultured. The morphology of cultured cells was characterized by immunohistochemical analysis and the results demonstrated that primary renal tubular epithelial cells with the expected morphology and distribution were successfully separated and cultured from SD rats. HBx gene pcDNA3.1/myc vector and empty vector were constructed and transfected into cells as HBx and empty groups, respectively. Following transfection, the mRNA and protein levels of HBx, cyclin A, cyclin D1 and cyclin E in cells were determined by reverse transcription-quantitative polymerase chain reaction and western blot analysis, respectively. The results demonstrated that following HBx gene transfection, the mRNA and protein levels of HBx, cyclin A, cyclin D1 and cyclin $\mathrm{E}$ in cells were significantly upregulated, compared with the empty control group $(\mathrm{P}<0.05)$. Furthermore, cell apoptosis and the cell cycle were evaluated by Annexin V-fluorescein isothiocyanate/propidium iodide staining and flow cytometry. HBx gene transfection significantly inhibited the cell apoptosis $(\mathrm{P}<0.05)$, promoted cell cycle progression from the $\mathrm{G} 1$ to $\mathrm{S}$ phase and arrested the cell cycle in the $\mathrm{S}$ phase. Therefore, the results of the present study indicated that HBx gene transfection may regulate the apoptosis and cell cycle of primary renal tubular epithelial cells by affecting the
\end{abstract}

Correspondence to: Professor Wenlun Han, Department of Nephrology, Tongde Hospital of Zhejiang Province, 234 Gucui Road, Hangzhou, Zhejiang 310012, P.R. China

E-mail: hanwenlun01@163.com

${ }^{*}$ Contributed equally

Key words: hepatitis $\mathrm{B}$ virus, hepatitis $\mathrm{B}$ virus $\mathrm{X}$ protein, nephropathy, renal tubular epithelial cells, cell cycle, cyclin expression of cyclins. The results of the present study may improve the understanding of pathogenesis associated with HBV-associated glomerulonephritis, and may also provide insight and theoretical support for the future design and development of drugs for the treatment of hepatitis B virus.

\section{Introduction}

The transmission of hepatitis B virus (HBV) is a major issue threatening public health worldwide, particularly in China. It is reported that in China, up to $10-20 \%$ of the population carry HBV (1). HBV infection leads to damage to multiple organs and in vivo lesions, with the kidney being among the susceptible vital organs. The morbidity of HBV-associated glomerulonephritis (HBV-GN) is a leading cause of secondary nephropathy in China (2). Nephron loss induced by HBV infection and the consequent imbalance of cell cycle progression are considered to be major factors in the pathogenesis of HBV-GN. Cell cycle progression is strictly regulated by genes and proteins that have been investigated extensively, including cyclin A, cyclin E, p16 and p21 proteins. When cell cycle progression is disturbed, the consequent cellular apoptosis or non-programmed cell death have an important role in renal injury.

The HBV gene is comprised of four open reading frames, which include the preS/S, P, C and X genes (3). The HBV X (HBx) gene guides the synthesis of the HBx protein, which is a unique non-structural protein of HBV. The HBx protein is a type of functional protein possessing various regulatory effects, such as transactivation, and it has an important regulatory role in virus replication, cell infection, cellular apoptosis induction and the triggering of inflammatory responses (4-10). Although HBx has been demonstrated to exert effects on the regulation of cell proliferation, the detailed regulatory mechanisms of the HBx protein are yet to be established.

Previous research conclusions concerning HBx have been based on transformed or immortalized cell lines, and the genetic and regulatory mechanisms of the cell cycle of these cell lines are often altered. This may misguide the understanding of the mechanisms underlying the effects of the HBx protein on the physiology of renal tubular epithelial cells and HBV replication. In order to exclude the variation from the transformed and immortalized cell lines and investigate the effects of HBx protein on the cell cycle progression of renal cells, primary renal tubular epithelial cells are more suitable 
model cells. However, to the best of our knowledge, no previous reports have employed primary renal tubular epithelial cells as model cells to investigate the effects of $\mathrm{HBx}$ in renal cells.

Therefore, the current study investigated the specific mechanisms underlying the effects of $\mathrm{HBx}$ protein in the regulation of the cell cycle progression of primary renal tubular epithelial cells by determining the expression levels of cell cycle-associated proteins following transfection of rat primary renal tubular epithelial cells with a $\mathrm{HBx}$ gene eukaryotic expression vector.

\section{Materials and methods}

Materials. Cellulose acetate membrane was purchased from EMD Millipore (Billerica, MA, USA). Collagenase type I, penicillin-streptomycin and epithelial cell growth factor were purchased from Sigma-Aldrich (Merck KGaA, Darmstadt, Germany). Rabbit anti-Cyclin A monoclonal antibody (cat. no. ab181591; 1:2,000), rabbit anti-Cyclin D1 monoclonal antibody (cat.no.ab134175; 1:10,000), rabbit anti-Cyclin Epolyclonal antibody (cat. no. ab71535; 1:2,000), rabbit anti-cytokeratin 18 monoclonal antibody (cat. no. ab32118; 1:400) and rabbit anti-HBx polyclonal antibody (cat. no. ab39716; 1:2,000) were all obtained from Abcam (Cambridge, MA, USA). Mouse anti- $\beta$ actin (cat. no. TA-09; 1:2,000), horseradish peroxidase (HRP) conjugated goat anti-mouse IgG (cat. no. ZB-2305; 1:2,000), HRP goat anti-rabbit IgG (ZB-2301; 1:2,000) secondary antibodies and concentrated DAB kit (cat. no. ZLI-9017) were purchased from ZSGB-Bio, Inc. (Beijing, China). HRP conjugated polymer anti-rabbit IgG antibody (cat. no. SV0002; 1:100) was purchased from Boster Biological Technology (Pleasanton, CA, USA). Dulbecco's Modified Eagle's Medium (DMEM), fetal bovine serum (FBS) and trypsin were purchased from Gibco (Thermo Fisher Scientific, Inc., Waltham, MA, USA). KpnI and EcoRV endonucleases, T4 DNA ligase and TOP10 competent cells were from Beijing Transgen Biotech Co., Ltd. (Beijing, China). SuperSignal West Pico Chemiluminescent Substrate was purchased from Thermo Fisher Scientific, Inc. Epithelial cell medium (EpiCM) was obtained from Nanjing KeyGen Biotech Co., Ltd. (Nanjing, Jiangsu, China). The HiFiScript cDNA Synthesis kit was purchased from CW Biotech Co., Ltd. (Beijing, China). TRNzol and Mini and Maxi Plasmid kits were from Tiangen Biotech Co., Ltd. (Beijing, China). TaKaRa Ex Taq was purchased Takara Biotechnology Co., Ltd. (Dalian, China). Annexin V-fluorescein isothiocyanate (FITC)/propidium iodide (PI) apoptosis kit (cat. no. KGA105) was purchased from Nanjing KeyGen Biotech Co., Ltd. (Nanjing, China).

Animals. A total of 2 male Sprague Dawley (SD) rats (weight, 220 and $240 \mathrm{~g}$; aged 8 weeks old) were purchased from the Experimental Animal Center of the Medical College of Zhejiang University (Hangzhou, China). The rats were raised with free access to water and food in a sterile environment of $25-28^{\circ} \mathrm{C}, 40-60 \%$ relative humidity and a $12 / 12 \mathrm{~h}$ light/dark cycle. Prior to the experiment, the rats were fasted for $12 \mathrm{~h}$ with free access to water. The study protocol was reviewed and approved by the Institutional Animal Care and Use Committee of Zhejiang University and was in accordance with the guidelines established by the Chinese Council of Animal Care (11).
Separation and culture of primary renal tubular epithelial cells. Rats were euthanized by cervical vertebra dislocation and immersed in $70 \%$ (v/v) ethanol for 2-3 min. Two kidneys were removed. Renal cortexes were cut into pieces $(\sim 1 \mathrm{~mm})$ and ground on 80 mesh sieves. Following 2-3 washes with PBS, residue on the sieves was collected, pipetted repeatedly and centrifuged at $1,000 \mathrm{xg}$ and room temperature for $5 \mathrm{~min}$. The supernatant was discarded. The pellet was resuspended in $2 \mathrm{ml}$ collagenase type-I $(1 \mathrm{mg} / \mathrm{ml})$ and incubated under vibration in a $37^{\circ} \mathrm{C}$ water bath for $30 \mathrm{~min}$. The mixture was centrifuged at $1,000 \mathrm{x} \mathrm{g}$ at room temperature for $3 \mathrm{~min}$. The supernatant was discarded again and the pellet was resuspended in $4 \mathrm{ml}$ DMEM containing 10\% (v/v) FBS and 1\% (v/v) penicillin-streptomycin (10 $\mathrm{mg} / \mathrm{ml}$ penicillin and $10 \mathrm{mg} / \mathrm{ml}$ streptomycin). Subsequently, primary cells were routinely cultured for 3 days at $37^{\circ} \mathrm{C}$ and $5 \% \mathrm{CO}_{2}$, followed by washing with PBS three times. Trypsin buffer $(2 \mathrm{ml}, 0.25 \%)$, and a mixture of trypsin $(0.25 \%)$ and EDTA $(0.02 \%)$, were dropwise added to immerse the cells. Cells were subsequently trypsinized in a $37^{\circ} \mathrm{C}$ water bath for $1-2 \mathrm{~min} .2 \mathrm{X}$ EpiCM containing 10\% (v/v) FBS, 1\% (v/v) epithelial cell growth factor $(1 \mu \mathrm{g} / \mathrm{l})$ and $1 \%(\mathrm{w} / \mathrm{v})$ penicillin-streptomycin $(10 \mathrm{mg} / \mathrm{ml}$ penicillin and $10 \mathrm{mg} / \mathrm{ml}$ streptomycin) was immediately added. Cells were subsequently subcultured at a ratio of 1:2.

Morphology characterization by immunohistochemical analysis. Cells $\left(2.5 \times 10^{5}\right)$ were seeded into 24 -well plates and covered by coverslips. Following the culturing of cells for $36 \mathrm{~h}$ and 7 days time intervals, they were removed and washed with PBS three times. Cells were subsequently fixed in $4 \%(\mathrm{w} / \mathrm{v})$ cold paraformaldehyde at $4^{\circ} \mathrm{C}$ for $30 \mathrm{~min}$, permeabilized in $0.5 \%(\mathrm{w} / \mathrm{v})$ Triton $\mathrm{X}-100$ at $37^{\circ} \mathrm{C}$ for $5 \mathrm{~min}$ and incubated in deionized water containing $3 \%(\mathrm{w} / \mathrm{v}) \mathrm{H}_{2} \mathrm{O}_{2}$ at room temperature for $10 \mathrm{~min}$. Cells were subsequently blocked using $5 \%$ bovine serum albumin (Beyotime Institute of Biotechnology, Jiangsu, China) at $37^{\circ} \mathrm{C}$ for $30 \mathrm{~min}$. After rinsing with PBS, cells were incubated in anti-cytokeratin 18 primary antibody (1:400) buffer at $4^{\circ} \mathrm{C}$ overnight. Cells were incubated in an equal volume of PBS in the control group. After rinsing with PBS, cells were incubated in HRP conjugated polymer anti-rabbit IgG antibody (1:100) buffer at $37^{\circ} \mathrm{C}$ for $1.5 \mathrm{~h}$. Subsequently, development using a concentrated DAB kit, rinsing, counterstaining using $0.1 \%$ hematoxylin at room temperature for 3 min, dehydration using ethanol, transparentization using xylol and mounting were performed in sequence. The coverslips were observed under an optical microscope (XDZ-103; Shanghai Tiancheng Medical Flow Technology Co., Ltd., Shanghai, China) with Image Analysis 11.0 software (Beijing Changheng Rongchuang Technology Co., Ltd., Beijing, China).

Construction of HBx gene pcDNA3.1/myc vector. Primers were designed according to HBV genomic sequence of ayr subtype in GenBank (12) (https://www.ncbi.nlm.nih. gov/pubmed/6300776) and the HBx gene was amplified via polymerase chain reaction (PCR) using TaKaRa Ex Taq according to the manufacturer's protocol. The thermocycling conditions used were as follows: Pre-denaturation for $3 \mathrm{~min}$ at $96^{\circ} \mathrm{C}$; followed by 23 cycles of denaturation for $20 \mathrm{sec}$ at $95^{\circ} \mathrm{C}$, annealing for $20 \mathrm{sec}$ at $58^{\circ} \mathrm{C}$, elongation for $30 \mathrm{sec}$ at $72^{\circ} \mathrm{C}$; and final extension for $1 \mathrm{~min}$ at $72^{\circ} \mathrm{C}$. The sequences of primers were as follows: Forward, 5'-GGGGTACCGTGGCAGAGG 
Table I. Primers for reverse transcription-quantitative polymerase chain reaction.

\begin{tabular}{ll} 
Gene & \multicolumn{1}{c}{ Primer sequence, 5'-3' $^{\prime}$} \\
\hline Cyclin E & F: ATCTGGCGGTTGACTTT \\
& R: GGCAGCGATGAAGAGTG \\
Fyclin A & R: ACGAACATGTCGCTAGTGGT \\
& F: CAGAAGTGCGAAGAGGAA \\
Cyclin D1 & R: GAAGCCAGGAACATACAAG \\
FBx & F: CACTTCGCTTCACCTCTGC \\
& R: TCGGTCGTTGACATTGCTG \\
$\beta$-actin & F: ATCGTCCACCGTAAATGC \\
& R: TGAAGTGGTAGTCGGGTG
\end{tabular}

F, forward; R, reverse; HBx, hepatitis B virus X protein.

TGAAAAAGTTGC-3' and reverse, 5'-GCCGATATCCTA ACATTGAGATTCCCGAG-3'. The forward and reverse primers contained KpnI and EcoRV endonuclease cutting sites, respectively. The pcDNA3.1/myc plasmid (Miaolingbio Bioscience \& Technology Co., Ltd., Wuhan, China) and the amplified HBx segments were managed by double enzyme digestion with restriction endonucleases KpnI and EcoRV. Electrophoresis was performed and the enzyme-digested products were recovered and purified using an agarose gel DNA recovery kit (Tiangen Biotech Co., Ltd., Beijing, China), according to the manufacturer's protocol. Subsequently, ligation was performed with T4 DNA ligase. The ligated products were transformed into TOP10 competent cells and the cells were cultured based on ampicillin screening. Finally, DNA sequencing was performed by Sangon Bioetch Co., Ltd. (Shanghai, China) for identification.

Extraction of the HBx gene vector. Saved strains were inoculated into $200 \mathrm{ml} \mathrm{LB}$ media (Qingdao Hope Bio-Technology Co., Ltd., Qingdao, China) containing $100 \mathrm{mg} / \mathrm{l}$ ampicillin at $37^{\circ} \mathrm{C}$ for $14 \mathrm{~h}$. Colonies containing plasmids on the LB plates were removed and added into $2 \mathrm{ml}$ LB media containing ampicillin $(100 \mu \mathrm{g} / \mathrm{ml})$. When the optical density value of the bacterial solution reached $\sim 2$, the solution was centrifuged at $10,000 \mathrm{x} \mathrm{g}$ at room temperature for $1 \mathrm{~min}$ to collect the bacteria pellets. The pcDNA3.1/myc plasmids were extracted using Mini and Maxi Plasmid kits plasmid according to the manufacturer's protocol.

HBx gene transfection. When primary renal tubular epithelial cells, cultured in $4 \mathrm{ml}$ DMEM containing 10\% (v/v) FBS and $1 \%(\mathrm{v} / \mathrm{v})$ penicillin-streptomycin $(10 \mathrm{mg} / \mathrm{ml}$ penicillin and $10 \mathrm{mg} / \mathrm{ml}$ streptomycin), in 6-well plates reached $90 \%$ confluency $\left(1.2 \times 10^{6}\right)$, the culture medium was replaced by serum-free DMEM medium and cells were incubated again at $37^{\circ} \mathrm{C}$ for $48 \mathrm{~h}$. The plasmid was gently mixed with Lipofectamine 3000 (Invitrogen; Thermo Fisher Scientific, Inc.) and culture medium according to the manufacturer's protocol. The mixture was added into the 6 -well plates (5 $\mu \mathrm{g}$ plasmid/well). Subsequently, cells were incubated at $37^{\circ} \mathrm{C}$ for $4 \mathrm{~h}$ followed by the replacement of the culture medium with medium containing serum at $37^{\circ} \mathrm{C}$ for another $48 \mathrm{~h}$.

Determination of HBx and cell cycle-associated gene expression by reverse transcription-quantitative PCR (RT-qPCR). Cells were divided into three groups: Control, empty and HBx. Cells transfected with empty plasmid pcDNA3.1(+) and recombinant plasmid pcDNA3.1(+)-HBx were designated as the empty and HBx groups, respectively. Cells without transfection served as the control group. Total RNA was extracted from cells $\left(1.2 \times 10^{6}\right)$ with TRNzol, according to the manufacturer's protocol. Primers sequences are presented in Table I. Reverse transcription was performed with a HiFiScript cDNA Synthesis kit, according to the manufacturer's protocol. qPCR was performed using UltraSYBR Mixture (cat. no. CW0957M; CWBIO, Inc., Beijing, China). Thermocycling parameters were set as follows: Pre-denaturation for $10 \mathrm{~min}$ at $95^{\circ} \mathrm{C}$, followed by 40 cycles of denaturation for $10 \mathrm{sec}$ at $95^{\circ} \mathrm{C}$, annealing for $30 \mathrm{sec}$ at $51.2^{\circ} \mathrm{C}$ and elongation for $30 \mathrm{sec}$ at $72^{\circ} \mathrm{C}$. $\beta$-actin served as internal control and the relative level to $\beta$-actin was calculated accordingly using classical $2^{-\Delta \Delta C q}$ method (13).

Determination of $H B x$ and cell cycle-associated protein expression by western blot analysis. Cells were also divided into three groups for western blot analysis: Control, empty and HBx. Following transfection, the culture medium was discarded and cells were washed two times with ice-precooled PBS. Subsequently, cells $\left(1.2 \times 10^{6}\right)$ were scraped and centrifuged at $2,000 \mathrm{x} \mathrm{g}$ and $4^{\circ} \mathrm{C}$ for $5 \mathrm{~min}$. Cell pellets were collected and resuspended in RIPA lysis buffer (cat. no. C1053; Applygen Technologies, Inc., Beijing, China) containing 10\% (w/v) phenylmethanesulfonyl fluoride and $1 \%(\mathrm{w} / \mathrm{v})$ phosphatase inhibitors for $20 \mathrm{~min}$. This mixture was centrifuged at $10,000 \mathrm{x}$ g at room temperature for $10 \mathrm{~min}$ and the supernatant was collected to obtain total cell protein. Gel loading buffer $(5 \mathrm{X})$ was added into total protein and the mixture was boiled for $5 \mathrm{~min}$ to denature proteins. Subsequently, proteins ( $2 \mu \mathrm{g}$ per lane) were loaded to perform 10\% SDS-PAGE electrophoresis. Proteins were transferred to a polyvinylidene difluoride membrane at $4^{\circ} \mathrm{C}$. The membrane was incubated in blocking buffer that consisted of TBS with $0.1 \%$ Tween-20 (TBST) containing $5 \%(\mathrm{w} / \mathrm{v})$ nonfat-dried milk on a horizontal shaker at room temperature for $1.5 \mathrm{~h}$. Subsequently, the membrane was immersed in 3-5 ml with rabbit anti-Cyclin A antibody, rabbit anti-Cyclin D1, rabbit anti-Cyclin E, rabbit anti-HBx, and mouse anti- $\beta$ actin primary antibodies at $4^{\circ} \mathrm{C}$ overnight. TBST was used to rinse the membrane three times for $10 \mathrm{~min}$ each time. The membrane was incubated with HRP conjugated goat anti-mouse $\operatorname{IgG}$ and goat anti-rabbit $\operatorname{IgG}$ secondary antibodies at room temperature for $1.5 \mathrm{~h}$. The membrane was rinsed with TBST three times for 10 min each time. Following the addition of ECL solution, the membrane was exposed on a gel imaging system (ChemiDoc XRS; Bio-Rad Laboratories, Inc.). Gray values were determined using Quantity One software (v4.6.2; Bio-Rad Laboratories, Inc.).

Evaluation of cell apoptosis and the cell cycle by flow cytometry. Renal tubular epithelial cells in logarithmic phase were divided into three groups: Control, empty and HBx. Following transfection, cells were cultured for a further $24 \mathrm{~h}$ 


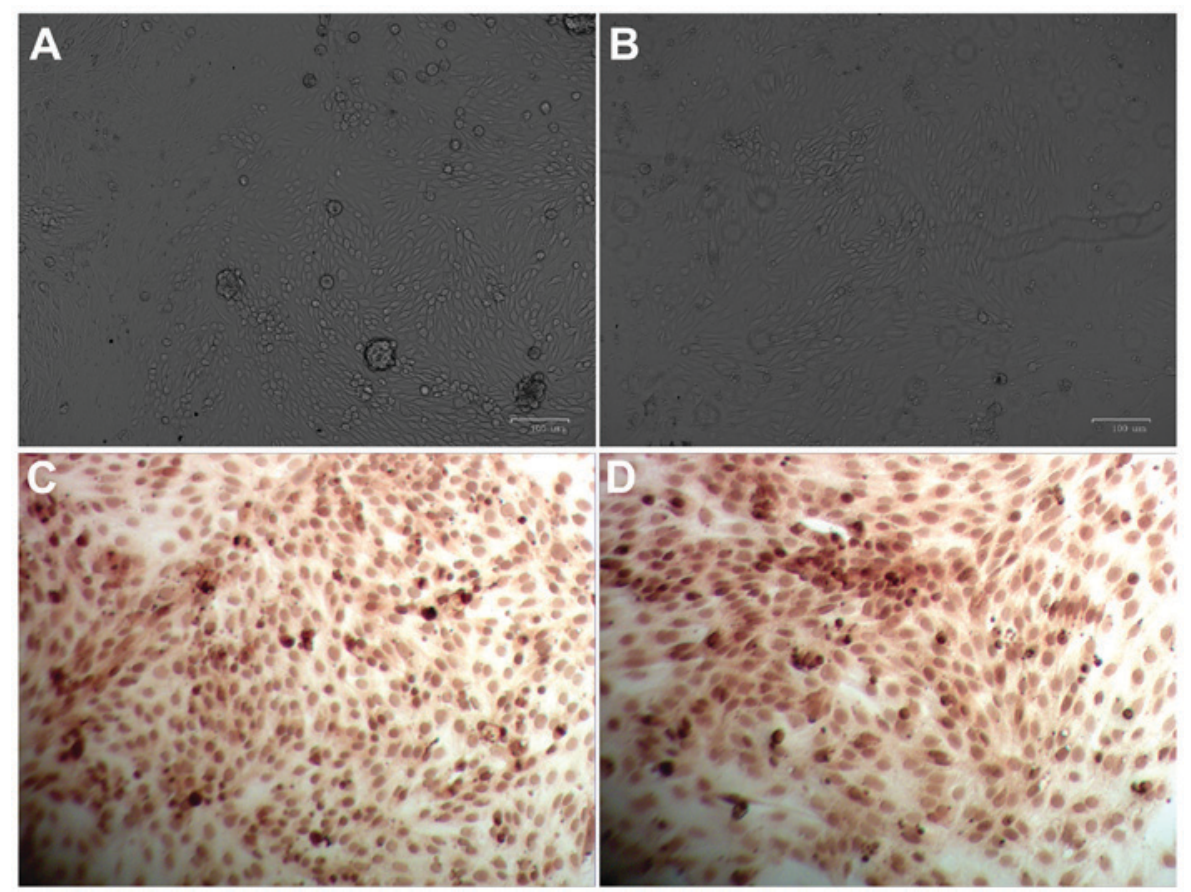

Figure 1. Morphology characterization of primary renal tubular epithelial cells. Light microscopy images captured following culture for (A) $36 \mathrm{~h}$ and (B) 7 days. Immunohistochemical images captured following culture for (C) $36 \mathrm{~h}$ and (D) 7 days. At $36 \mathrm{~h}$ time intervals, the epithelioid cell population presented with an 'island-like' distribution; and at 7 day time intervals, cells were distributed as typical multilateral cobblestones with tight arrangements and high transparency. Brown granules exhibited non-uniform and scattered distributed in the cytoplasm and perinuclear region of cells. Magnification, x20.

$\left(1.2 \times 10^{6}\right)$ and trypsinized for $5 \mathrm{~min}$. Cells were centrifuged at $1,200 \mathrm{x} \mathrm{g}$ at room temperature for $5 \mathrm{~min}$, washed and resuspended in $500 \mu \mathrm{l}$ binding buffer (1X). Cells were gently mixed with Annexin V-FITC $(5 \mu \mathrm{l})$ and incubated at $4^{\circ} \mathrm{C}$ in the dark for $30 \mathrm{~min}$. After gentle mixing with PI $(5 \mu \mathrm{l})$, the mixture was incubated at $4^{\circ} \mathrm{C}$ in the dark for another $5 \mathrm{~min}$. Finally, the cell suspension was immediately evaluated on a flow cytometer (BD FACSCalibur; BD Biosciences, Franklin Lakes, NJ, USA). Data were analyzed using CellQuest software (v.17; BD Biosciences). In order to investigate the cell cycle, cells were cultured following transfection at $37^{\circ} \mathrm{C}$ for a further $24 \mathrm{~h}\left(1.2 \times 10^{6}\right)$ and subsequently trypsinized for $5 \mathrm{~min}$. Cell were fixed in pre-cooled $70 \%$ ethanol at $4^{\circ} \mathrm{C}$ for $3 \mathrm{~h}$. Cells were then centrifuged at $1,200 \mathrm{x} \mathrm{g}$ at room temperature for $5 \mathrm{~min}$, washed with PBS and then resuspended in $1 \mathrm{ml} \mathrm{PI}(50 \mu \mathrm{g} / \mathrm{ml})$ containing $0.5 \%$ Triton $\mathrm{X}-100$ at room temperature in the dark for $30 \mathrm{~min}$. Finally, the cell suspension was evaluated using a flow cytometer (BD FACSCalibur; BD Biosciences), and data were subsequently analyzed using CellQuest software (v.17; BD Biosciences).

Statistical analysis. All experiments were independently repeated three times and data are presented as the mean + standard deviation. Statistical analysis was performed using SPSS 18.0 software (SPSS, Inc., Chicago, IL, USA). Statistical comparisons among groups were performed by one way analysis of variance followed by Tukey's post-hoc test. $\mathrm{P}<0.05$ was considered to indicate a statistically significant difference.

\section{Results}

Morphology characterization of primary renal tubular epithelial cells. In the present study, cells that exhibited various intensities of non-uniform, scattered brown staining in the cytoplasm and perinuclear region, and with a shape resembling multilateral cobblestones with mutually tight arrangements, were considered to be verified as renal tubular epithelial cells. Images of primary renal tubular epithelial cells are presented in Fig. 1. When primary cells were cultured for $12 \mathrm{~h}$, their anchorage growth was observed. After 24-36 h, epithelioid cells emerged from the periphery of the anchorage area and the whole cell population exhibited an 'island-like' distribution (Fig. 1A). A total of 6-7 days post-primary culture, cells grew all over the bottom of the culture bottle. At this time-point, cells were observed to resemble the shape of typical multilateral cobblestones with tight arrangements and high transparency (Fig. 1B). The present study employed immunohistochemical analysis to determine the levels of cytokeratin 18 specifically expressed in renal tubular epithelial cells and the results demonstrated the presence of brown granules with a non-uniform and scattered distribution in the cytoplasm and perinuclear region (Fig. 1C and D). These results indicated that these cells were verified to be renal tubular epithelial cells.

mRNA expression levels of HBx and cell cycle-associated genes. The mRNA levels of HBx and the cell cycle-associated genes cyclin A, cyclin D1 and cyclin E in renal tubular epithelial cells was determined by RT-qPCR. No significant differences were observed between the mRNA levels in the control and empty groups ( $\mathrm{P}>0.05$; Fig. 2). However, renal tubular epithelial cells in the $\mathrm{HBx}$ group exhibited significantly higher mRNA levels of HBx, cyclin A, cyclin D1 and cyclin E compared with the empty group $(\mathrm{P}<0.05$; Fig. 2$)$.

HBx and cell cycle-associated protein levels. The protein levels of HBx and the cell cycle-associated proteins cyclin A, cyclin D1 


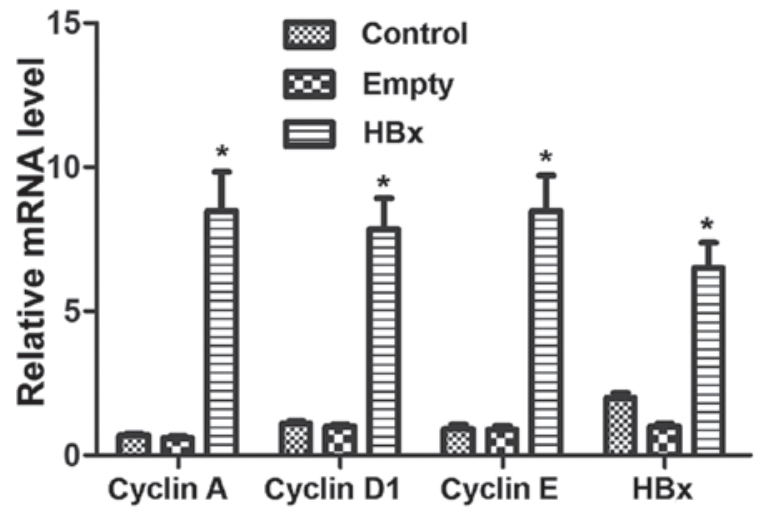

Figure 2. mRNA levels of HBx, cyclin A, cyclin D1 and cyclin E genes in renal tubular epithelial cells in the control, empty and HBx groups were determined by reverse transcription-quantitative polymerase chain reaction. Cells transfected with empty plasmid pcDNA3.1(+) and recombinant plasmid pcDNA3.1(+)-HBx were designated as the empty and HBx groups, respectively. Cells without transfection served as the control group. ${ }^{*} \mathrm{P}<0.05$ vs. empty group. $\mathrm{HBx}$, hepatitis $\mathrm{B}$ virus $\mathrm{X}$ protein.

and cyclin $\mathrm{E}$ in renal tubular epithelial cells were assessed by western blot analysis. As demonstrated in Fig. 3A, similar blots for $\beta$-actin were observed among the control, empty and HBx groups, indicating that the western blotting method was reliable. An obvious dark blot for $\mathrm{HBx}$ was observed in the $\mathrm{HBx}$ group, but no blot traces of $\mathrm{HBx}$ were observed in the control and empty groups. The quantified results demonstrated similar protein levels of cyclin A, cyclin D1 and cyclin E between the control and empty groups ( $\mathrm{P}>0.05$; Fig. 3B). Notably, in the HBx group, the protein expression of cyclin A, cyclin D1 and cyclin E were significantly upregulated compared with the empty group ( $\mathrm{P}<0.05$; Fig. 3B). Quantitatively, HBx protein was scarcely detected in the control and empty groups, while following HBx gene transfection, renal tubular epithelial cells exhibited significantly increased expression of HBx protein (Fig. 3B).

Cell apoptosis. The cell apoptosis of renal tubular epithelial cells in the control, empty and HBx groups was evaluated by Annexin V-FITC/PI double staining and flow cytometry results are presented in Fig. 4. The apoptotic rates of cells in the control, empty and HBx groups were 7.02 $\pm 1.02,6.96 \pm 0.86$ and $2.80 \pm 0.24 \%$, respectively. Cells in the control and empty groups exhibited similar apoptotic rates, demonstrating that the transfection of the empty plasmid did not affect the apoptosis of renal tubular epithelial cells. Compared with the empty group, the apoptotic rate was markedly reduced by $>60 \%$ following the transfection of the plasmid containing the $\mathrm{HBx}$ gene $(\mathrm{P}<0.05$; Fig. 4), indicating that $\mathrm{HBx}$ gene transfection was able to effectively suppress the apoptosis of renal tubular epithelial cells.

Cell cycle. The cell cycle of renal tubular epithelial cells in the control, empty and HBx groups was evaluated by flow cytometry and results are presented in Fig. 5. The green peak area on the left, yellow peak area in the middle and blue peak area on the right represent cells in G1, S and G2 phases, respectively. The distribution of the cell cycle in the control group was comprised of G1 89.38\% (Freq G1), S 14.15\% (Freq S) and G2 0.74\% (Freq $\mathrm{G} 2)$; the majority of cells were in the presynthetic phase, a few cells were in the synthetic phase and a limited number of
A

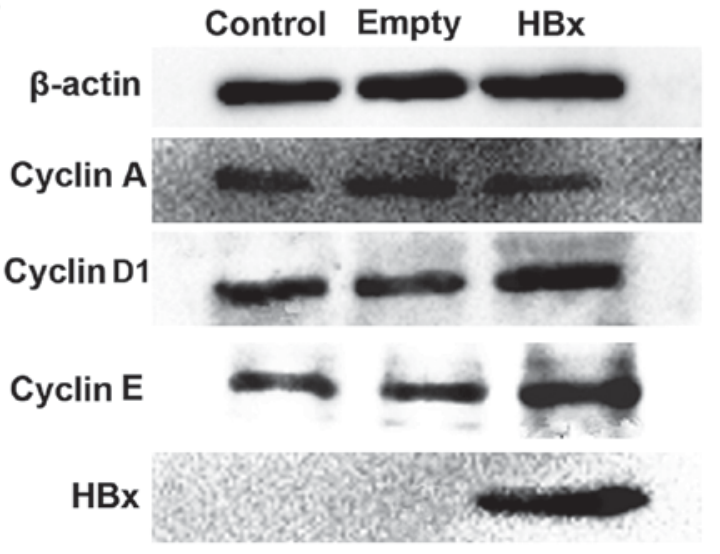

B

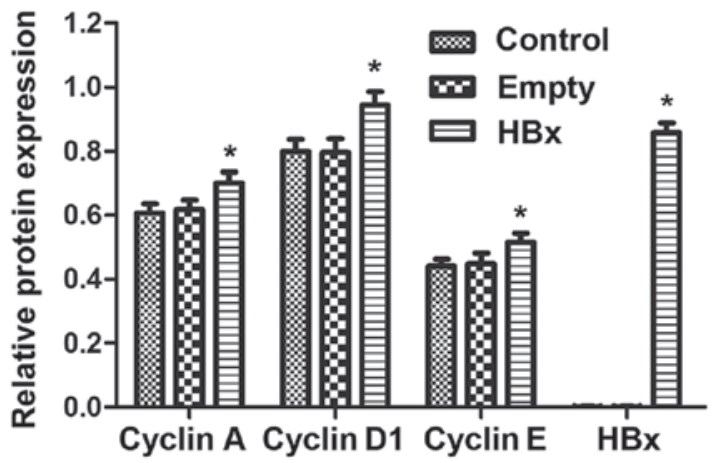

Figure 3. Protein levels of HBx, cyclin A, cyclin D1 and cyclin E in renal tubular epithelial cells in the control, empty and HBx groups were assessed western blot analysis. (A) Representative western blot bands for cyclin A, cyclin D1, cyclin E and HBx in control, empty and HBx groups are presented. (B) Densitometric analysis was performed to quantify the protein expression levels and perform statistical analysis. Cells transfected with empty plasmid pcDNA3.1(+) and recombinant plasmid pcDNA3.1(+)-HBx were designated as the empty and HBx groups, respectively. Cells without transfection served as the control group. ${ }^{*} \mathrm{P}<0.05$ vs. empty group. $\mathrm{HBx}$, hepatitis $\mathrm{B}$ virus $\mathrm{X}$ protein.

cells were in the postsynthetic phase. In the empty group, cells numbers in the $\mathrm{S}$ and $\mathrm{G} 2$ phases were marginally augmented. However, when cells were transfected with the HBx gene, G1 and $\mathrm{S}$ phase cell percentages were markedly decreased and increased, respectively, while the percentage in the G2 phase was similar to the control group. The results indicated that $\mathrm{HBx}$ gene transfection promoted the progression of renal tubular epithelial cells from the G1 to S phase.

\section{Discussion}

Chronic hepatitis B in patients is usually associated with various types of extrahepatic damage, and HBV-GN is one of the most common forms of extrahepatic damage. However, an understanding of the risk factors and pathogenesis of HBV-GN remain unclear, and effective preventive and therapeutic strategies are also yet to be established (14). At present, direct infection of the kidney by HBV and subsequent immunological dysfunction induced by the infection are considered to be the major pathogenic causes of HBV-GN $(15,16)$. In the nephridial tissues of patients with HBV-GN, obvious tubulointerstitial lesions were identified, which presented as inflammatory cell infiltration and interstitial fibrosis (17). The severity of 

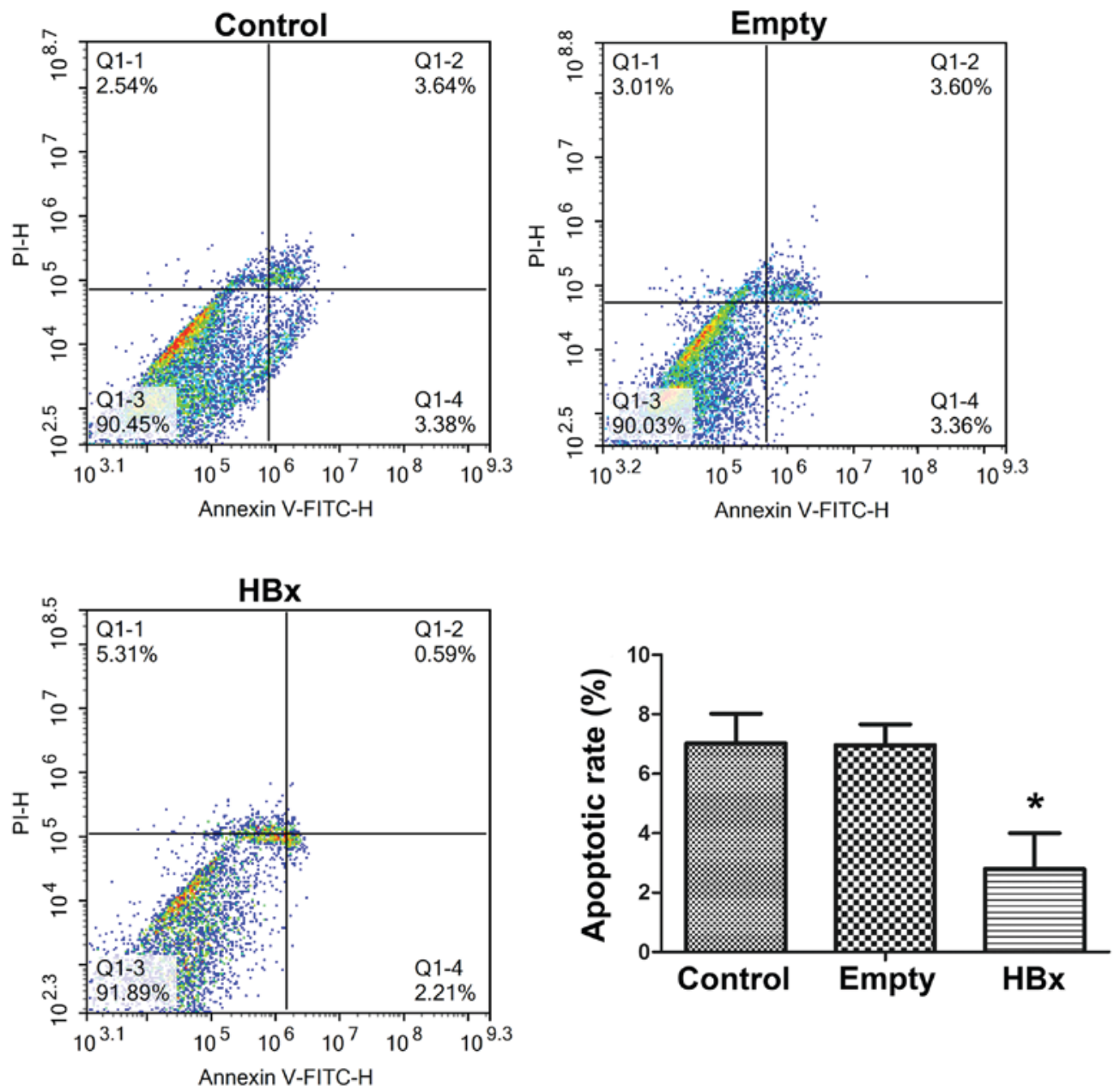

Figure 4. Cell apoptosis of renal tubular epithelial cells in the control, empty and HBx groups was evaluated by Annexin V-FITC/PI double staining and subsequent flow cytometry. Cells transfected with empty plasmid pcDNA3.1(+) and recombinant plasmid pcDNA3.1(+)-HBx were designated as the empty and HBx groups, respectively. Cells without transfection served as the control group. Q1-2 and Q1-4 quadrants represent cells undergoing apoptosis. "P $<0.05$ vs. empty group. HBx, hepatitis B virus X protein; FITC, fluorescein isothiocyanate; PI, propidium iodide.

interstitial lesions was reported to be positively associated with the infiltration degree of inflammatory cells and atrophy of renal tubular epithelial cells (HK-2 cells) was observed in the pathological tissues (17). The results of previous studies indicated that human renal tubular epithelial cells cultured in vitro were susceptible to $\mathrm{HBV}$ and $\mathrm{HBV}$ enhanced the secretion of transforming growth factor- $\beta 1$ by human renal tubular epithelial cells $(18,19)$. Other reports revealed that HBx protein was expressed in the renal tubular epithelial cells of patients with HBV-GN and was primarily distributed in the cytoplasm $(20,21)$. Furthermore, its expression level in the renal tubular epithelial cells was demonstrated to be higher compared with in glomerular cells $(20,21)$. Therefore, HBx may be principally replicated and transcribed in situ within renal tubular epithelial cells and the damage of renal tubular epithelial cells may be generated in this process.

In order to elucidate the damage mechanism of $\mathrm{HBx}$ on renal tubular epithelial cells, a renal tubular epithelial cell model with $\mathrm{HBx}$ transfection was established. It was previously reported that $\mathrm{HBx}$ transfection promoted the transdifferentiation of HK-2 cells, indicating that HBx may alter the microenvironment of HK-2 cells and facilitate epithelial-mesenchymal transition $(22,23)$. Although the evolution from the damage of renal tubular epithelial cells to the final reduction of cell number was regulated by multiple mechanisms, the ultimate effect was altered cell cycle progression (24). The cell cycle is composed of a resting phase (G0), DNA presynthetic phase (G1), DNA synthetic phase (S), DNA postsynthetic phase (G2) and mitotic phase $(\mathrm{M})$. Intervention in cell cycle progression influences the replication of HBV and, in addition, HBx protein was demonstrated to alter the cell apoptosis process of renal tubular epithelial cells during the pathological process of renal tubular interstitial fibrosis induced by HBV (25). Therefore, analysis of alterations in the expression of cell cycle-associated proteins and confirmation of the association with HBV replication level in vivo are required to investigate the mutual effects between HBx protein and the cell cycle.

Cyclins are a family of proteins with cell cycle-specific or temporal expression and catabolism. The cell cycle is regulated by various cyclins. Cyclin A regulates the transition from $\mathrm{G} 1$ to $\mathrm{S}$ phase, which is associated with DNA replication (26), while cyclin D1 and cyclin E are associated with G1 phase. Upregulation of cyclin A, cyclin D1 and cyclin E will facilitate the cell transition from G1 to $S$ phase (27). The tumor suppressor genes p16 and p21 compete with multiples cyclins to bind to various cyclin-dependent kinase sites, inhibit the 

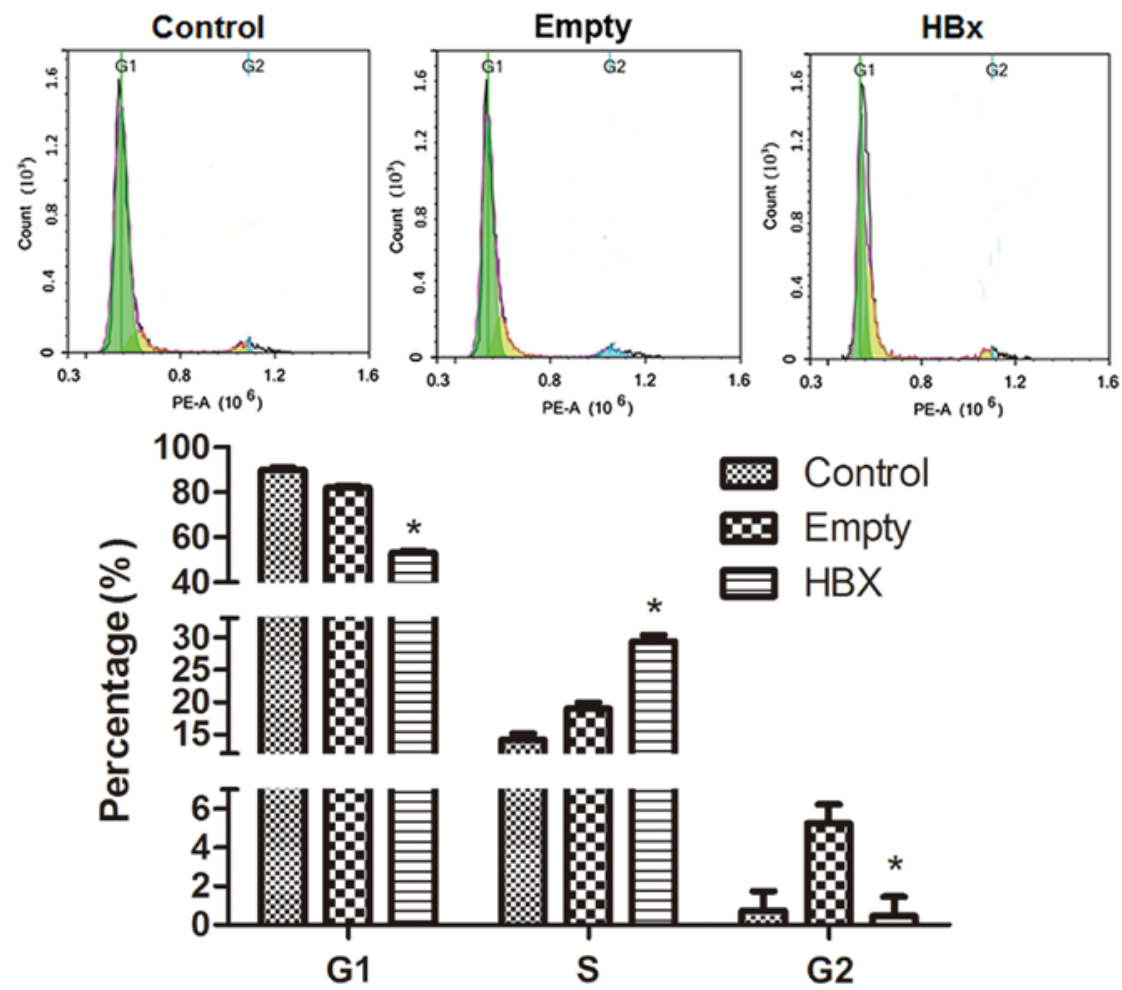

Figure 5. The cell cycle distribution of renal tubular epithelial cells in the control, empty and HBx groups was evaluated by flow cytometry. Cells transfected with empty plasmid pcDNA3.1(+) and recombinant plasmid pcDNA3.1(+)-HBx were designated as the empty and HBx groups, respectively. Cells without transfection served as the control group. ${ }^{*} \mathrm{P}<0.05$ vs. empty group. HBx, hepatitis B virus $\mathrm{X}$ protein.

activation of cyclin and arrest the cell cycle in the G1 phase, which consequently regulates cells division and differentiation, and prevents the excessive proliferation of cells $(28,29)$.

As a type of trans-acting factor with extensive biological functions, the HBx protein has been reported to activate intracellular signal transduction systems and regulate the cell proliferation through binding to cell transcription factors (30). In the past, it was widely considered that HBx may accelerate cell cycle progression and cell proliferation through shortening the G0/G1 phase. However, Clippinger et al (6) demonstrated that the effect of $\mathrm{HBx}$ on cell apoptosis was bidirectional in hepatocytes. Zhai et al (4) further revealed that the effect of HBx on the cell cycle was dose-dependent, but the specific mechanisms of this effect remain unclear (31).

Therefore, in the present study, HBx was transfected into primary renal tubular epithelial cells. Following HBx transfection, the mRNA expression of cyclin A, cyclin D1 and cyclin E were markedly increased, and the corresponding protein levels were also upregulated. These results indicated that HBx may influence the cell cycle progression of renal tubular epithelial cells by regulating the expression of cyclins and causing a rapid transition of cells from G0 to S phase via G1 phase. Thus, the present study also investigated the levels of cell apoptosis and cell cycle distribution, and the results demonstrated that $\mathrm{HBx}$ transfection markedly promoted the progression of renal tubular epithelial cells from the G1 to S phase and suppressed the cell apoptosis, which was consistent with the results of RT-qPCR and western blot analysis of cyclin expression. These results indicated that $\mathrm{HBx}$ protein may function in altering cell cycle progression.

Although the current study demonstrated that HBx protein may act on cyclin A, cyclin E and cyclin D1 to regulate the cell cycle of renal tubular epithelial cells, the further specific regulation mechanism requires future exploration. For example, the results of the present study do not indicate whether the $\mathrm{HBx}$ protein affects the expression of cyclin A, cyclin $\mathrm{E}$ and cyclin D1 by competitive binding or altering upstream signaling. However, dysfunction of the tumor suppressor gene p53 was reported to be associated with the overexpression of HBx $(32,33)$. Our future studies will focus on the effects of p53, p21 and p16 genes on the HBx protein and HBV replication in primary renal tubular epithelial cells.

The present study revealed the effects of $\mathrm{HBx}$ on the cell cycle progression of primary renal tubular epithelial cells by transfection with HBx gene pcDNA3.1/myc vector. We also hypothesized that the HBx gene may integrate into the genomic DNA of hosts by recombination. As a multifunctional protein, HBx may function in the proliferation or apoptosis of host cells through stimulating signal transduction pathways in the cytoplasm and the activation of transcription factors in the nucleus (34). However, further studies are required to confirm whether the Hbx gene is able to integrate into the genomic DNA of host cells.

In conclusion, primary renal tubular epithelial cells of rats were separated and cultured to investigate the effect of $\mathrm{HBx}$ gene transfection on the expression of cyclins, cell apoptosis and the cell cycle. Consequently, HBx gene transfection was demonstrated to regulate the apoptosis and cell cycle of primary renal tubular epithelial cells by influencing the expression of cyclins. These results may improve the understanding of the pathogenesis of HBV-GN and may also provide insight and theoretical support for the design and development of future hepatitis B virus drugs. 


\section{Acknowledgements}

Not applicable.

\section{Funding}

The present study was financially supported by the 2015 General Medical and Health Research Program of Zhejiang Province (Class A), Health and Family Planning Commission of Zhejiang Province, China (grant no. 2015KYA043).

\section{Availability of data and materials}

The analyzed data sets generated during the study are available from the corresponding author on reasonable request.

\section{Authors' contributions}

WH and ML designed the study and wrote the manuscript. WH, ML, MH, YZhu, YZho, HD, GH, LL, QC and YL performed the experiments. MH, YZhu, YZho and HD collected and analyzed data.

\section{Ethics approval and consent to participate}

The study protocol was reviewed and approved by the Institutional Animal Care and Use Committee of Zhejiang University (Hangzhou, China).

\section{Consent for publication}

Not applicable.

\section{Competing interests}

The authors declare that they have no competing interests.

\section{References}

1. Zhang Q and Xue C: Research progress in pathogenesis of hepatitis B virus associated nephritis. Med Recap: 2543-2545, 2013.

2. Yi Z, Jie YW and Nan Z: The efficacy of anti-viral therapy on hepatitis B virus-associated glomerulonephritis: A systematic review and meta-analysis. Ann Hepatol 10: 165-173, 2011.

3. Seeger C and Mason WS: Hepatitis B virus biology. Microb Mol Biol Rev 64: 51-68, 2000.

4. Zhai LL, Liu J and Xie YH: Dose-dependent modulation of cell apoptosis by hepatitis B virus X protein. J Microb Infect: 72-77, 2011.

5. Xia LM, Huang WJ, Wu JG, Yang YB, Zhang Q, Zhou ZZ, Zhu HF, Lei P, Shen GX and Tian DA: HBx protein induces expression of MIG and increases migration of leukocytes through activation of NF-kappa B. Virology 385: 335-342, 2009.

6. Clippinger AJ, Gearhart TL and Bouchard MJ: Hepatitis B virus $\mathrm{X}$ protein modulates apoptosis in primary rat hepatocytes by regulating both NF-kappa B and the mitochondrial permeability transition pore. J Virology 83: 4718-4731, 2009.

7. Tan C, Guo H, Zheng M, Chen Y and Huang W: Involvement of mitochondrial permeability transition in hepatitis $\mathrm{B}$ virus replication. Virus Res 145: 307-311, 2009.

8. He P, Shang H, Li D and Feng G: Effects of HBx gene on proliferation and apoptosis of human renal tubular epithelial cells. Chin J Nephrol 29: 380-381, 2013.

9. Chen HY, Tang NH, Lin N, Chen ZX and Wang XZ: Hepatitis $\mathrm{B}$ virus $\mathrm{X}$ protein induces apoptosis and cell cycle deregulation through interfering with DNA repair and checkpoint responses. Hepatol Res 38: 174-182, 2008.
10. Huang YQ, Wang LW, Yan SN and Gong ZJ: Effects of cell cycle on telomerase activity and on hepatitis B virus replication in HepG22.2.15 cells. Hepatobiliary Pancreat Dis Int 3: 543-547, 2006.

11. General Administration of Quality Supervision, Inspection and Quarantine of China: Laboratory animal-Guideline of welfare ethical review (Draft for approval). Mar 18, 2017.

12. Ono Y, Onda H, Sasada R, Igarashi K, Sugino Y and Nishioka K: The complete nucleotide sequences of the cloned hepatitis B virus DNA; subtype adr and adw. Nucleic Acids Res 11: 1747-1757, 1983.

13. Livak KJ and Schmittgen TD: Analysis of relative gene expression data using real-time quantitative PCR and the 2(-Delta Delta C (T)) method. Methods 25: 402-408, 2001.

14. He P, Li H, Li D and Feng G: HBx gene promotes apoptosis in HK-2 cells through regulating apoptosis-relatedprotein ratio of Bax/Bcl-2. J Chin Med Univer 43: 38-44, 2014.

15. An S, Zhang R, Yang W, Zhou H, Zhang Z, Yang Y and Guo X: Research advances in hepatitis B virus-associated glomerulonephritis. J Clin Hepatol 32: 366-369, 2016.

16. Jiang W, Xu Y, Guan G, Ma R and Dong H: Renal amyloidosis and hepatitis B virus-associated glomerulonephritis in a patient with nephrotic syndrome. Chin Med J (Engl) 127: 1199, 2014.

17. Deng CL, Song XW, Liang HJ, Feng C, Sheng YJ and Wang MY: Chronic hepatitis B serum promotes apoptotic damage in human renal tubular cells. World J Gastroenterol, 12: 1752-1756, 2006.

18. Zhu N, Zhou Y, Yuan WJ, Liu J, Shang MH, Wang L and Gu LJ: Toll-like receptor 4 deposition and its significance in hepatitis B virus associated nephropathy. Zhonghua Nei Ke Za Zhi 50: 1008-1012, 2011 (In Chinese).

19. Han WL and Huang ZX: Experimental study of direct pathogenic effects of hepatitis B virus on human tubular kidney cell. J Wenzhou Med College, 38: 144-147, 2008.

20. Han WL and Huang ZX: Infection of hepatitis B virus on human tubular kidney cells in vitro. J Zhejiang Med Univer 32: 1148-1150, 2010.

21. Hong L, Zhang J, Li Q, Min J, Lu J, Li F, Li H and Guo S: Role of NF- $\kappa B$ activiation by MHBst167/HBx in human renal tubular cells. Chin J Nephrol Dial Transplant 19: 135-141, 2010.

22. Hong L, Zhang J, Min J, Lu J, Li F, Li H, Guo S and Li Q: A role for MHBst167/HBx in hepatitis B virus-induced renal tubular cell apoptosis. Nephrol Dial Transplant 25: 2125-2133, 2010.

23. Zhou Y, Wang X, Yuan W and Zhu N: Effect of hepatitis B virus $\mathrm{X}$ gene on transdifferentiation of human proximal tubular epithelial cells. Chin J Nephrol 28: 956-960, 2012.

24. Zhou Y, Zhu N, Wang X, Wang L, Gu LJ and Yuan WJ: The role of the toll-like receptor TLR4 in hepatitis B virus-associated glomerulonephritis. Arch Virol 158: 425-433, 2013.

25. Marshall CB and Shankland SJ: Cell cycle regulatory proteins in podocyte health and disease. Nephron Exp Nephrol 106: e51-e59, 2007.

26. Madden CR and Slagle BL: Stimulation of cellular proliferation by hepatitis B virus X protein. Dis Markers 17: 153-157, 2001.

27. Zhan SD and Huang JX: Progression of Cyclin A, PTEN, Survivin and p27 expression in esophageal cancer. J Modern Oncol: pp2245-2248, 2014.

28. Li YJ and Li YY: Advances in the research of cyclin E and p27 in gynecological. Foreign Med Sci (Obstet Gynecol Fascicle): 177-180, 2007.

29. Lin T: Expression and significance of Cell cycle regulatory proteins in the hepatitis B virus associated nephrits. Fujian Med Univer, Fuzhou: pp52, 2011.

30. Wu RS: Cell cycle regulation of p16, cdk4 and its role in the formation of middle ear cholesteatoma. J Basic Med Shandong Univer: 53-55, 2004

31. Lu HZ, Liu D and Zhou JH: Effects of HBV X protein on glomerular mesangial cell proliferation and proinflammation factor expression. Chongqing Med 40: 2227-2230, 2011.

32. Matsuda $Y$ and Ichida T: Impact of hepatitis B virus $X$ protein on the DNA damage response during hepatocarcinogenesis. J Med Mol Morphol 42: 138-142, 2009.

33. Park SG, Min JY, Chung C, Hsieh A and Jung G: Tumor suppressor protein p53 induces degradation of the oncogenic protein HBx. Cancer Lett 282: 229-237, 2009.

34. Bouehard MJ and Sehneider RJ: The enigmatic X gene of hepatitis B virus. J Virol 78: 12725-12734, 2004.

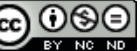

This work is licensed under a Creative Commons Attribution-NonCommercial-NoDerivatives 4.0 International (CC BY-NC-ND 4.0) License. 